\title{
IMPLEMENTASI METODE KRITIK INTRINSIK DALAM MENINGKATKAN KEMAMPUAN MEMBACA AL-QURAN
}

\author{
Shobah Shofariyani Iryanti, Fitri Liza \\ Program Studi Pendidikan Agama Islam, Fakultas Agama Islam, \\ Universitas Muhammadiyah Prof. Dr. Hamka Jakarta \\ email : shobahshofariyani@uhamka.ac.id
}

\begin{abstract}
Muhammadiyah 1 junior high school Depok hold a tadarus to read the Koran every Friday. However, the method applied is not appropriate and not right with the interests of students. Even students do not understand the various methods of reading the Koran. This is where researchers apply the intrinsic criticism method with the Al-Muyassar approach to improve the ability to read the Qur'an in this student of Muhammadiyah 1 junior high school Depok. This type of research is descriptive qualitative. Data collected includes primary data. And the study population was all students of the Muhammadiyah 1 junior high school Depok of grade eight. Data analysis in this study was observed by students and students of Muhammadiyah 1 junior high school Depok. And the results of this study will be used as a reference to implement the method of reading Almuyassar's intrinsic criticism in the Muhammadiyah 1 junior high school Depok.
\end{abstract}

\section{Keywords : The method of reading the Qur'an, The method of Intrinsic Criticism, education Islamic Religion}

\begin{abstract}
ABSTRAK
Mts Muhammadiyah 1 Depok mengadakan tadarus membaca Al-Quran setiap hari jumat. Akan tetapi, metode yang diterapkan tidak sesuai dan belum tepat dengan minat peserta didik. Bahkan peserta didik belum paham macam-macam metode dalam membaca Al-Quran . Disinilah peneliti menerapkan Metode kritik intrinsik dengan pendekatan Almuyassar untuk meningkatkan kemampuan membaca Al-Quran Pada siswa Mts Muhammadiyah 1 Depok. Jenis penelitian ini adalah kualitatif Deskriptif. Data yang dikumpulkan meliputi data primer. Dan Populasi penelitian adalah seluruh siswa Mts Muhammadiyah1 Depok kelas VIII. Analisis data dalam penelitian ini dengan observasi siswa dan siswi Mts muhammadiyah 1 Depok. Hasil penelitian ini akan dijadikan acuan untuk mengimplementasikan metode membaca Al-Quran kritik intrinsik Almuyassar di Mts muhammadiyah 1 Depok.
\end{abstract}

\section{Kata kunci: Metode membaca Al-quran, Metode Kritik Intrinsik, Pendidikan Agama Islam}




\section{PENDAHULUAN}

Pendidikan Agama Islam adalah usaha sadar atau kegiatan yang disengaja dilakukan untuk membimbing sekaligus mengarahkan peserta didik menuju terbentuknya pribadi yang utama (insan kamil) berdasarkan nilai-nilai etika Islam dengan tetap memelihara hubungan baik terhadap Allah swt (Hablumminallah) dan sesama manusia (hablumminannas), dirinya sendiri dan sekitarnya. Pendidikan Agama bertujuan untuk mengembangkan potensi peserta didik agar menjadi manusia yang beriman dan bertakwa kepada Tuhan Yang Maha Esa. Pendidikan Islam juga merupakan salah satu bidang studi yang mendapat banyak perhatian dari para Ilmuan, dalam pendidikan Islam terdapat berbagai masalah yang kompleks dan memerlukan penanganan segera. (Abuddin Nata. 2009:333)

Hal yang sangat diperhatikan dalam pengajaran Pendidikan Agama Islam adalah bacaan Alquran. Membaca Al-Quran adalah ibadah yang diberi pahala oleh Allah kepada pembacanya jika cara membacanya benar dan serta mengikut kaedah bacaan dan hukum tajwid.

Secara garis besar metode yang dicetuskan oleh Al-Khulli dalam sebuah pengajaran membaca Alquran dibagi menjadi dua yang pertama adalah Metode kritik ekstrinsik atau yang membahas tentang sesuatu yang ada disekitar teks. Hal ini seperti kajian tentang munculnya sebuah karya, yang meliputi aspek sosiologis-geografis, religi, kultur ataupun politiknya juga kajian terhadap sejarah karya dengan berbagai atribut periodisasi, sehingga mampu menemukan hubungan antara karya, latar belakang kemunculannya, dan semangat intelektual yang dikandungnya. Sedangkan yang kedua adalah metode kritik intrinsik yang ditujukan pada teks itu sendiri, dengan analisis linguistik yang teliti kita diharapakan untuk mengungkap makna yang terkandung didalamnya. Al-Khulli mengatakan bahwa kata-kata Al-quran harus didefinisikan berdasarkan atas apa yang dipahami oleh Nabi Muhammad saw dan para sahabatnya. (Moch. Nur Ichwan, 2003:43)

Al-quran karim adalah firman Allah SWT yang tidak mengandung kebatilan sedikitpun. Alquran memberi petunjuk jalan yang lurus dan memberikan bimbingan kepada ummat manusia dalam menempuh perjalanan hidupnya. Petunjuk-petunjuk agama tersebut mengenai pengaturan berbagai kehidupan manusia sebagaimana terdapat di dalam sumber ajaran-Nya yakni Al-quran dan hadist yang tampak sangat ideal dan Agung. ( Abuddin Nata. 2009:1). Adapun kesulitankesulitan dalam membaca Al-quran dikarenakan belum adanya metode yang tepat dalam meningkatkan kemampuan membaca Al-quran khususnya pada siswa/i Mts Muhammadiyah 1 Depok. Disamping itu juga penelitian ini ingin melihat bagaimana implementasi langkah metode membaca Al-quran dengan metode kritik intrinsik dalam meningkatkan kemampuan membaca Al-quran pada siswa/i Mts Muhammadiyah 1 Depok. 
Berpijak dari permasalahan di atas, mendorong penulis untuk melakukan penelitian di Mts Muhammadiyah 1 Depok, khususnya pada kegiatan membaca Al-quran dengan menitik beratkan pada implementasi metode kritik intrinsik pendekatan Al-Muyassar yang terdapat mata pelajaran PAI di sekolah ini.

\section{PEMBAHASAN}

\section{Makna Al-Quran}

Al-Quran Karima dalah firman Allah yang tidak mengandung kebatilan sedikitpun. AlQuran memberi petunjuk jalan yang lurus dan memberi bimbingan kepada ummat manusia di dalam menempuh perjalanannya. Dalam hadist Nabi "Sebaik-baiknya kamu adalah orang yang mempelajari Al-quran dan mengajarkanya” HR.Bukhari. (Abu Izzah, 2014: 4)

M. Quraish Sihab, menyatakan bahwa: 'Perintah membaca merupakan sesuatu yang paling berharga yang pernah dan dapat diberikan kepada umat manusia. Membaca dalam aneka maknanya adalah syarat utama adanya pengembangan ilmu dan teknologi, serta syarat membaca untuk membangun peradaban. (M. Quraish Shihab, 1996: 6)

Kesejarahan Al-quran tidak hanya berbicara mengenai bagaimana diturunkan, akan tetapi pembacaan dan penelusuran terhadap kesejarahan Al-quran mencakup banyak aspek. Para sarjana kontemporer memasukan berbagai bidang kesejarahan seperti kodifikasi, tradisi pengajaran dan penyampaian, publikasi dan bahkan studi orientalis terhadap Qur'an. (Millatī, 2017: 6)

Setelah wafatnya Nabi Muhammad saw, umat Islam mempunyai dua panduan dalam menjalankan hidup, yakni Al-quran dan As-sunnah. Sebagai pedoman tertinggi umat Islam yang tidak diragukan kebenarannya tentulah manusia melakukan berbagai upaya agar kedua hal tersebut benar-benar dipahami lalu mempraktekkan ajaran-ajaran didalamnya. Upaya-upaya untuk memahami Al-quran khususnya telah melahirkan berbagai macam teori dan metode. Namun pemakaian teori dan metode tersebut cenderung tidak bebas nilai, para pengkaji Al-quran seringkali memahami ayat-ayat Al-quran berdasarkan latar belakang ideologi pandangan politik mereka serta menggunakan ayat-ayat Al-quran sebagai dalil pembenaran atas aktivitas ideologis, ekonomis dan politis yang mereka lakukan. Padahal, menurut Nasr Hamid Abu Zayd, penafsiran ayat-ayat suci itu haruslah tidak dibarengi dengan embel-embel karena ayat Al-quran tidak bisa diperkosa atas nama kepentingan apapun sehingga memahami dan menafsirkannya pun harus dengan objektif dan teliti. (Moch. Nur Ichwan, 2003: 45)

Belajar membaca sebagaimana pendapatnya Mulyono Abdurrahman, lebih baik kalau dimulai sejak kecil. Hal ini karena membaca merupakan komponen utama dalam memahami dan 
menambah ilmu pengetahuan dan wawasan, karena dengan membaca orang akan bertambah informasi-informasi yang dapat menambah wawasan pengetahuan. Membaca merupakan suatu keterampilan yang kompleks, rumit, yang mencakup atau melibatkan serangkaian keterampilanketerampilan yang lebih kecil. Dengan kata lain keterampilan membaca mencakup tiga komponen:

1. Pengenalan terhadap aksara serta tanda-tanda baca; merupakan suatu keterampilan mengenal bentuk-bentuk yang disesuaikan dengan mode gambar, gambar disuatu lembaran, di lingkungan garis dan titik-titik yang berpola dan teratur rapi.

2. Korelasi aksara beserta tanda-tanda baca dengan unsur-unsur linguistik yang formal: merupakan suatu untuk menghubungkan tanda-tanda hitam di atas kertas yakni gambargambar berpola tersebut.

3. Hubungan lebih lanjut dan A dan B dengan makna atau meaning mencakup keseluruhan keterampilan membaca, pada dasarnya merupakan intelektual. (Henry.G Tarigan, 1979.:10)

Pelajaran Al-quran di Jenjang Madratsah Tsanawiyah merupakan bagian dari Pendidikan Agama Islam, salah satu pelajaran pada jenjang pendidikan Menengah Pertama pada satuan pendidikan Madrasah Tsanawiyah yang mengkhususkan pada pengkajian terhadap materi ilmuilmu agama Islam yang bersumber dari Al-quran dan Hadits. Pada mata pelajaran Al-quran yang masuk dalam mata pelajaran PAI, siswa banyak sekali diajarkan tentang cara memahami dan menghayati kandungan ayat-ayat Al-quran mulai dari cara menulis yang baik, membaca yang benar, menyalin dan lain-lain agar siswa dapat menggali nilai-nilai Al-quran lebih mendalam.

Membaca Al-quran adalah ibadah yang diberi pahala oleh Allah kepada pembacanya jika cara membacanya benar dan serta mengikut kaidah bacaan dan hukum tajwid. Frekuensi membaca Al-quran merupakan sarana yang sangat penting untuk mengetahui suatu ilmu, baik ilmu agama maupun ilmu pengetahuan umum. Seorang siswa harus memiliki keterampilan membaca di segala bidang tiada batas untuk dapat menemukan prestasi yang hendak dicapai dan hal itu dalam melakukan membaca perlu mendapat motivasi dari orang tua dan guru agar membaca belajar Al-quran dapat berhasil dalam mengembangkan keberhasilan ilmu pengetahuan. (Ach. Slamet, Juni 2015: 84) 


\section{Metode Membaca Al-quran}

Al-quran adalah firman Allah yang disampaikan oleh Malikat Jibril as sesuai redaksinya kepada nabi Muhammad saw dan diterima oleh umat secara tawatur. (M. Quraish Shihab, Mukjizat Al-qur'an, (Bandung, Mizan 2003:43).

Dalam hal ini langkah-langkah untuk mempelajarinya harus tersusun secara terencana dan sistematis dengan menggunakan teknik dan metode tertentu dalam proses pembelajaran Alquran untuk mencapai tujuan yang diinginkan sangat penting agar cara membacanya benar serta mengikut kaidah bacaan dan hukum tajwid.

Menghormati Al-quran sebagai firman Allah maka membacanya harus memiliki adab yang baik. Diantara adab membaca Al-quran yang terpenting adalah :

1. Selalu menjaga keikhlasan.

2. Tidak mencari popularitas atau berniat menjadikan sarana pencarian nafkah.

3. Disunnahkan membaca Al-quran setelah berwudhu.

4. Tempat yang baik membaca dan menghafal Al-quran adalah tempat yang baik dan suci.

5. Disunnahkan membaca dengan khusyu dengan menghadap kiblat.

6. Waktu membaca Al-quran mulut dalam keadan bersih dan sebaiknya berkumur-kumur terlebih dahulu.

7. Disunnahkan terlebih dahulu membaca ta'āwuz dan basmalah

8. Membaca dengan tartil.

9. Memikirkan terhadap ayat-ayat yang dibaca .

10. Membacanya dengan suara yang keras dan dengan irama lagu tartil yang baik. (Jurnal Ilmiah Didaktika Vol. XIV, No. 2, Februari 2014)

\section{Metode Kritik Intrinsik}

Secara garis besar metode yang dicetuskan oleh Al-Khulli dalam sebuah pengajaran membaca Al-quran dibagi menjadi dua yang pertama adalah Metode Kritik Ekstrinsik atau yang membahas tentang sesuatu yang ada disekitar teks. Hal ini seperti kajian tentang munculnya sebuah karya, yang meliputi aspek sosiologis-geografis, religi, kultur ataupun politiknya juga kajian terhadap sejarah karya dengan berbagai atribut periodisasi, sehingga mampu menemukan hubungan antara karya, latar belakang kemunculannya, dan semangat intelektual yang 
dikandungnya. Sedangkan yang kedua adalah Metode Kritik Intrinsik yang ditujukan pada teks itu sendiri, dengan analisis linguistik yang teliti kita diharapkan untuk mengungkap makna yang terkandung didalamnya. Al-Khulli mengatakan bahwa kata-kata Al-quran harus didefinisikan berdasarkan atas apa yang dipahami oleh Nabi Muhammad saw dan para sahabatnya. (Moch. Nur Ichwan .2003: 43)

Metode bacaan instrinsik tersebut sudah ada sejak zaman nabi, contohnya adalah ketika nabi ditanya tentang surat Al-Baqarah 187: 'Maka makan minumlah engkau hingga terang bagimu benang putih dari benang hitam, yaitu fajar. Nabi kemudian ditanya oleh Uday bin Hatim: 'apakah dua benang tersebut seperti benang yang sudah dikenal, yakni benang hitam dan putih?' Nabi menjawab: 'yang dimaksud benang hitam adalah gelapnya malam dan benang putih adalah terangya siang'. Peralihan makna frasa dari benang hitam dan benang putih menjadi gelapnya malam dan terangnya siang merupakan perubahan makna dari yang asasi menjadi makna majaz. (M. Nur Kholis Setiawan . 2006:130)

\section{METODOLOGI}

Penelitian ini adalah penelitian kualitatif deskriptif yang dilaksanakan di Mts Muhammadiyah 1 Depok. Untuk Populasi penelitian ini adalah seluruh siswa Mts Muhammadiyah1 Depok kelas VIII. Sedangkan, data yang dikumpulkan meliputi data primer. Akan tetapi, untuk pengambilan data primer diperoleh dari hasil observasi ke sekolah Mts muhammadiyah 1 Depok kelas VIII yang dilakukan peneliti. sedangkan untuk Analisis data dalam penelitian ini dengan observasi siswa dan siswi Mts muhammadiyah1 Depok.

\section{HASIL}

\section{Profil Sekolah}

MTs Muhammadiyah 1 Depok berdiri tahun 1979 dan kini telah memasuki usia 36 tahun, selama itu kiprah MTs Muhammadiyah 1 Depok telah dapat dirasakan oleh masyarakat. Lulusan MTs Muhammadiyah 1 Depok telah banyak yang berhasil dan bekerja dalam berbagai bidang kehidupan.MTs Muhammadiyah 1 Depok terus berupaya menjadikan Madrasah terdepan khususnya di Kota Depok. Untuk mencapai itu semua MTs Muhammadiyah 1 Depok akan meningkatkan pelayanan pembelajaran dengan inovasi pendidikan yang efektif, berbasis TIK dan Keagamaan.

Adapun visi dari Mts Muhammadiyah 1 Depok ini adalah Unggul dalam Prestasi, Teguh dalam Iman dan Taqwa, Terampil dalam Ilmu Pengetahuan dan Teknologi, serta Anggun dalam berakhlakul karimah. Sedangkan misi dari Mts Muhammadiyah 1 Depok ini adalah 
'Menyelenggarakan Pendidikan dan Pembelajaran yang Efektif Membangun Budaya dan Iklim Pendidikan yang Islami demi Terciptanya output siswa yang berprestasi dan berakhlakul karimah Menjadikan kader persyarikatan yang handal'.

Kurikulum yang diterapkan di Mts Muhammadiyah 1 Depok ini adalah Kurikulum Tingkat Satuan Pendidikan (KTSP), yaitu Kurikulum yang disesuaikan dengan kebutuhan lingkungan masyarakat dengan memadukan kurikulum yang berasal dari Dinas Pendidikan, Departemen Agama dan Muhammadiyah. Mempersiapkan peserta didik untuk memiliki kecakapan hidup (life skill) dan keterampilan berbahasa (bahasa Arab dan Inggris) serta kemampuan dalam teknologi informasi dan komunikasi yang dijiwai oleh spirit Islam.

\section{Metode Membaca Al-quran di Mts Muhammadiyah 1 Depok}

Mts Muhammadiyah 1 Depok mengadakan tadarus membaca Al-quran setiap hari Jumat. Dari situlah pihak sekolah memberikan pengayaan pada peserta didik khususnya dalam hal membaca Al-quran.

\begin{tabular}{|l|l|l|}
\hline \multicolumn{1}{|c|}{ No } & \multicolumn{1}{|c|}{ Kelas } & \multicolumn{1}{c|}{ Metode bacaan } \\
\hline 1 & VII & Metode Qiroati \\
\hline 2 & VIII & Metode Qiroati 1, 2, 3, 4, 5 \\
\hline 3 & IX & Metode Qiroati \\
\hline \multicolumn{2}{|c|}{ Gambar 1.1 Metode bacaan Alquran Mts.Muhammadiyah 1 Depok }
\end{tabular}

Dari hasil penelitian yang telah dilakukan di Mts Muhammadiyah 1 depok ini, peneliti belum melihat metode yang sesuai dan tepat dengan minat peserta didik yang ada. Bahkan peserta didik belum paham macam-macam metode dalam membaca Al-quran. Dan Kebanyakan mereka hanya membaca dengan memakai metode Qiroati nada 1, 2, 3, 4, 5 .

Peneliti melakukan penelitian di kelas VIII yang terdiri dari 5 kelas (VIII.1, VIII.2, VIII.3, VIII.4, VIII.5) dengan besaran jumlah kelas rata-rata 25 peserta didik. Survei yang dilakukan peneliti, bahwa $85 \%$ peserta didik jarang membaca Al-quran dalam keseharianya, tapi $15 \%$ dari mereka mengatakan membaca Al-quran sekali dalam sehari. Hal ini dilakukan karena rata-rata belum dan tidak menemukan metode yang tepat dan Nagham yang mudah dalam membaca bahkan menghafal Al-quran.

Dilihat dan diteliti hasil bacaan mereka, untuk mahojil huruf masih belum jeli dan belum memahami untuk kategori panjang pendek sebanyak 30\%, belum memahami untuk kategori bacaan tajwid 20\%, dan belum memahami untuk kategori kelancaran dalam membaca Alquran 
20\%. Bahkan ada diantara mereka yang belum hafal huruf hijaiyah sebanyak 10\%. Jadi, hanya $20 \%$ diantara mereka yang lancar dan terampil dalam membaca Al-quran.

\begin{tabular}{|c|c|c|c|c|c|}
\hline $\begin{array}{c}\text { Panjang } \\
\text { pendek }\end{array}$ & $\begin{array}{c}\text { Bacaan } \\
\text { tajwid }\end{array}$ & kelancaran & $\begin{array}{c}\text { Belum hafal huruf } \\
\text { hijaiyah }\end{array}$ & $\begin{array}{c}\text { Kurang } \\
\text { terampil }\end{array}$ & Terampil \\
\hline $30 \%$ & $20 \%$ & $20 \%$ & $10 \%$ & $80 \%$ & $20 \%$ \\
\hline
\end{tabular}

Gambar1.2 Hasil Bacaan siswa-siswi Mts Muhammadiyah 1 Depok sebelum menggunakan metode kritik intrinsik pendekatan Al-muyassar

Dari latar permasalahan tersebut peneliti memberikan pelatihan dan implementasi metode membaca Al quran Kritik Intrinsik dengan pendekatan Al-muyassar di Mts Muhammadiyah 1 depok Jawa Barat.

\section{Langkah Metode Kritik Intrinsik dalam meningkatkan kemampuan membaca}

\section{Al-Quran Pada siswa/i Mts Muhammadiyah 1 Depok.}

Peneliti mengadakan pelatihan Metode Kritik Intrinsik dengan pendekatan Al-muyassar untuk meningkatkan kemampuan membaca Al-Quran pada siswa/i Mts Muhammadiyah 1 Depok. Metode Almuyassar adalah metode membaca Alquran dengan mudah dan singkat.

Dari hasil survei yang peneliti lakukan di Mts Muhammadiyah 1 Depok, untuk mengatasi kebosanan dan kejenuhan dalam Membaca Al-quran peneliti menerapkan dan memperkenalkan metode kritik Intriksik dengan pendekatan Al-Muyassar. Metode ini memiliki 4 Strategi susunan yang terdiri atas:

\begin{tabular}{|l|l|}
\hline No & \\
\hline 1 & $\begin{array}{l}\text { Na na na } \\
\text { Na na na }\end{array}$ \\
\hline 2 & $\begin{array}{l}\text { Na na na } \\
\text { Na na na } \\
\text { Na na na }\end{array}$ \\
\hline 3 & $\begin{array}{l}\text { Na na na } \\
\text { Na na na } \\
\text { Na na na } \\
\text { Na na na }\end{array}$ \\
\hline
\end{tabular}




\begin{tabular}{|l|l|}
\hline \multirow{4}{*}{4} & Naa Na na \\
Na na na \\
Na na naa na \\
\cline { 2 - 3 } & Naa na na \\
Na na na \\
Na na na na \\
\cline { 2 - 3 } & Naa Na na \\
Na na na \\
Na na naa na \\
\cline { 2 - 3 } & Naa Na na \\
Na na na \\
Na na naa na
\end{tabular}

Gambar 1.3 Nagham Metode Kritik Intrinsik metode Al-Muyassar

\section{Efektifitas Metode Kritik Intrinsik Pendekatan Al-Muyassar dalam Meningkatkan} Kemampuan Membaca Al-Quran Pada siswa/i Mts Muhammadiyah 1 Depok.

Dari hasil penelitian tentang implementasi Metode Kritik Intrinsik pendekatan AlMuyassar pada siswa/i Mts Muhammadiyah 1 Depok, selama dari bulan September dan Oktober peneliti menjumpai beberapa dari mereka sangat antusias menerapkan metode Kritik Intrinsik pendekatan Al-Muyassar dalam membaca Al-Quran. Hal ini dilihat dari angket yang mereka isi. Selain itu peneliti juga mendapatkan data bacaan mereka meningkat dengan adanya metode ini. Diantaranya sebagi berikut: kesalahan membaca dalam bacaan panjang pendek dari $30 \%$ menjadi $10 \%$, kesalahan mengetahui bacaan tajwid dari $20 \%$ menjadi $10 \%$, kesalahan dalam kelancaran mahorijil huruf dari $20 \%$ persen menjadi $10 \%$ dan yang belum hafal huruf hijaiyah dari 10\% hanya sekitar $5 \%$ dan sisanya dan $65 \%$ mahir dan terampil dengan bacaan yang benar dalam membaca Al-quran dengan menggunakan metode kritik intrinsik pendekatan Al-Muyassar dari yang sebelumnya rata-rata diantara mereka $80 \%$ kurang terampil dalam membeca Al-Quran karena metode yang monoton.

\begin{tabular}{|l|c|c|}
\hline \multicolumn{1}{|c|}{ Kategori } & Sebelum & sesudah \\
\hline Panjang pendek & $30 \%$ & $10 \%$ \\
\hline Bacaan tajwid & $20 \%$ & $10 \%$, \\
\hline
\end{tabular}




\begin{tabular}{|l|c|c|}
\hline kelancaran & $20 \%$ & $10 \%$ \\
\hline Belum hafal huruf hijaiyah & $10 \%$ & $5 \%$ \\
\hline Kurang terampil & $\mathbf{8 0 \%}$ & $\mathbf{3 5 \%}$ \\
\hline Terampil & $\mathbf{2 0 \%}$ & $\mathbf{6 5 \%}$ \\
\hline Jumlah & $\mathbf{1 0 0 \%}$ & $\mathbf{1 0 0 \%}$ \\
\hline
\end{tabular}

Gambar. 1.4 Hasil Bacaan siswa-siswi Mts Muhammadiyah 1 Depok setelah mengimplementasi metode kritik intrinsik pendekatan Al-muyassar

Dari sinilah kita bisa mengetahui, bahwa efektivitas metode kritik intrinsik pendekatan Al-muyassar sangat berpengaruh dalam meningkatkan kemampuan membaca Al-quran pada siswa/i Mts Muhammadiyah 1 Depok.

\section{KESIMPULAN}

Dari pembahasan di atas maka peneliti dapat menyimpulkan hal-hal sebagai berikut:

1. Metode kritik intrinsik pendekatan Al-Muyassar adalah metode membaca Al-quran yang sangat mudah dan tepat untuk peserta didik di Mts.Muhammadiyah 1 Depok

2. Data bacaan mereka meningkat dengan adanya metode kritik intrinsik pendekatan AlMuyassar. Diantaranya sebagi berikut, kesalahan membaca dalam bacaan panjang pendek dari 30\% menjadi $10 \%$, kesalahan mengetahui bacaan tajwid dari $20 \%$ menjadi $10 \%$, kesalahan dalam kelancaran makhorijil huruf dari $20 \%$ persen menjadi $10 \%$ dan yang belum hafal huruf hijaiyah dari 10\% tinggal sekitar $5 \%$.

3. Sebesar $65 \%$ peserta didik mahir dan terampil dengan bacaan yang benar dalam membaca Al-quran dengan menggunakan metode kritik intrinsik pendekatan Al-Muyassar dari yang sebelumnya rata-rata diantara mereka $80 \%$ kurang terampil dalam membaca Al-Quran karena metode yang monoton.

Berdasarkan kesimpulan penelitian di atas maka ada beberapa hal yang perlu dilakukan dalam penerapan metode membaca Al-quran, antara lain:

1. Sekolah hendaknya melakukan pembaharuan metode membaca Al-quran, agar pembelajaran tidak monoton dan kaku.

2. Metode kritik intrinsik pendekatan Al-Muyassar bisa dijadikan metode yang tepat untukpembelajaran membaca Al-quran pada mata pelajaran PAI 
3. Disarankan untuk penelitian selanjutnya agar lebih memberikan metode yang bervariasi agar peserta didik lebih inovatif dan terampil dalam kelancaran membaca Al-Quran dengan baik dan benar sesuaidengan kaidah-kaidah membaca Al-Qur'an. 


\section{DAFTAR PUSTAKA}

Gede, Fitriani. 2014. JurnalI lmiah Vol.XIV. No.2. Februari.

Ichwan, Moch. Nur. 2003. Meretas Kesarjanaan Kritis Al-Qur'an; Teori Hermeneutika Nashr Abu Zayd. Jakarta Selatan: Penerbit Teraju.

Izzah, Abu . Tajwid dan Tahsin kaidah bacaaan ALquran. Jakarta: Mahkota kita 2014. Jakarta Selatan: Penerbit Teraju.

Millatī, Journal of Islamic Studies and Humanities Vol. 2, No. 1, Juni 2017: h. 65-83. DOI: 10.18326/millati.v2i1.65-83

Nata, Abuddin. 2009. Metodologi Studi Islam. Jakarta: PT Raja Grafindo. Ichwan, Moch. Nur. 2003. Meretas Kesarjanaan Kritis Al-Qur'an; Teori Hermeneutika Nashr Abu Zayd.

Satori, Djaman \& Qomariyah ,Aan. 2011. Metodologi penelitian Kualitatif. Bandung: Alfabeta.

Setiawan, M. Nur Kholis . 2006. Al-Qur'an Kitab Sastra Terbesar. Yogyakarta: Elsaq Press.

Shihab, M. Quraish . 1996. Wawasan Al-Qur'an.Jakarta: Mizan.

Slamet, Ach. 2015. Jurnal Tarbawi Vol. 12. No. 1. Januari - Juni .

Tarigan, Henry.G. 1979. Membaca sebagai Suatu Ketrampilan Berbahasa. Bandung:Angkasa.

M. Quraish Shihab, Mukjizat Al-qur'an, Bandung: Mizan 2003 